\title{
GUIOMAR TORREZÃO E AS CARTAS LISBONENSES: correspondência portuguesa nas páginas de $O$ Liberal do Pará
}

\author{
Maria Lucilena Gonzaga Costa Tavares \\ (UFPA) \\ https://orcid.org/0000-0001-8718-0494
}

\author{
Germana Maria Araújo Sales \\ (UFPA/CNPq) \\ https://orcid.org/0000-0002-2120-7364
}

\section{RESUMO}

A colonização portuguesa no Brasil se estendeu, de forma positiva, até o século XIX, quando os portugueses aqui radicados influenciaram na criação de vários jornais, como ocorreu na então província do Grão-Pará, onde os imigrantes portugueses que nela aportavam fundavam jornais com características próprias, dos quais se tornavam editores e redatores, oportunizando a democratização à leitura. Entre esses jornais, O Liberal do Pará registra um fato curioso que consiste na correspondência enviada exclusivamente para este jornal pela escritora lisbonense Guiomar Torrezão (26/11/1844 22/10/1898), desde o final da década de 1870. Neste sentido, o objetivo desse artigo é (re)apresentar as publicações da referida escritora - enquanto fonte documental - a fim de ratificar as contribuições da mulher nos jornais oitocentistas, especialmente aquelas endereçadas às leitoras paraenses.

PALAVRAS-CHAVE: Século XIX; O Liberal do Pará; Guiomar Torrezão. 


\section{GUIOMAR TORREZÃO AND THE LETTERS FROM LISBON: Portuguese correspondence on the pages of 0 Liberal do Pará}

\section{ABSTRACT}

The Portuguese colonization in Brazil spread positively until the nineteenth century when the Portuguese settled here influencedthe creation of several newspapers, as occurred in the province of Grão-Pará, where the Portuguese immigrants founded newspapers with characteristics of their own, from which they became editors and redactors, democratizing the reading. Among these newspapers, O Liberal do Pará registers a curious fact that consists of thecorrespondence sent exclusively to this newspaper by the writer Lisbon Guiomar Torrezão (11/26/1844 - 10/22/1898), since the end of the $1870 \mathrm{~s}$. In this sense, the purpose of this article is to (re)present the author's publications - as a documentary source in order to ratify women's contributions in the eighteenth-century newspapers, especially those addressed to the Paraense readers.

KEYWORDS: XIX Century; Paraense newspaper; Portuguese writer.

\section{Considerações Iniciais}

Na segunda metade do século XIX, a imprensa no Pará era profícua no número de periódicos diários que circulavam entre os leitores. Entre os vários jornais, havia aqueles de proprietários portugueses como $O$ Liberal do Pará, fundado em 10 de janeiro de 1869 e impresso na antiga Typografia do Jornal do Amazonas - A partir do segundo ano de publicação, em seu frontispício - foi conceituado como "Jornal Político, Commercial e Noticioso". Propriedade do português Manuel Antônio Monteiro ${ }^{1}$ serviu de Órgão do Partido Liberal do Pará, saiu de circulação após a proclamação as República, reaparecendo em 1890, sob o título de O Democrata.

Após seu lançamento, em 1879, O Liberal do Pará anunciou uma novidade nas letras femininas: as publicações, no espaço folhetim, das

\footnotetext{
${ }^{1}$ Correspondente de O Panorama, jornal literário e instrutivo da Sociedade Propagadora dos Conhecimentos Úteis.
} 
Cartas Lisbonenses, enviadas por Guiomar Torrezão que, a partir daquele período, assumiria a correspondência portuguesa do referido jornal. Em um total de doze cartas, publicadas entre 27 de julho de 1879 e 02 de maio de 1880, a autora reportava-se diretamente às leitoras paraenses de O Liberal, por meio do qual interpelava o público feminino a fim de estabelecer uma estreita relação de simpatia e amizade.

Obviamente que a colaboração da escritora portuguesa trazia bons lucros para o jornal, pelo caráter inovador do diálogo com as leitoras, independente se eram portuguesas ou não e, segundo, por enviar à imprensa paraense as novidades recorrentes na Europa, como moda, livros de escritores consagrados, estilo de vida d'além-mar, o que certamente chamava a atenção.

Guiomar (Delfina de Noronha) Torrezão (Lisboa, 26/11/1844 22/10/1898), conhecida pela alcunha de "Operária das Letras", foi a correspondente portuguesa mais atuante entre os jornais paraenses e uma das primeiras autoras a se manter financeiramente dos seus escritos, colaborando principalmente, como ficcionista, dramaturga, poetisa, ensaísta e jornalista em vários periódicos, mas foi sua participação no Almanaque de Lembranças Luso-Brasileiro que a tornou mais popular.

Sua estreia no mundo das letras foi em 1868, com o romance-folhetim Uma Alma de Mulher, publicado no jornal A Voz Feminina e em forma de livro no ano seguinte. Em 1872, publicou a edição de contos e novelas Rosas Pálidas, dois anos depois, em 1874, veio a lume o romance histórico A Família Albergaria. Na sequência, em 1875, outro volume de contos e crônicas intitulado Meteoros. Das várias tiragens dessa escritora portuguesa, convém citar a obra No teatro e na Sala (1881), prefaciada por Camilo Castelo Branco, e que reúne um conjunto de escritos, entre eles, contos, teatro, crítica literária, entre outros.

\section{As Cartas Lisbonenses}

O jornal O Liberal do Pará, no .169 , datado de domingo, 27 de julho de 1879, apresentou em sua primeira página, na seção "Noticiário", a seguinte publicação: "Chamamos a atenção dos nossos leitores para o nosso folhetim, primeiro da série que vai escrever a distinta literata portuguesa D. Guiomar Torrezão". Essa informação foi noticiada na mesma folha em que fora lançada a primeira carta da série Cartas Lisbonenses,

${ }^{2}$ In: BARROS, Thereza Leitão de. Escritoras de Portugal. Vol. II Lisboa, 1924. 
na seção "Folhetim" do referido jornal, a qual ocupou as cinco colunas e apresentou uma correspondente benevolente para com o público:

(...) poucas vezes na minha vida me tem preocupado o desejo de agradar como no momento presente em que, assentada à minha banca, no meu gabinete de trabalho, ponho no papel a primeira letra destas - Cartas Lisbonenses. (O Liberal do Pará, nº 169, 27/07/1879)

A correspondência, destinada para um público específico, mantinha o tom sedutor e envolvente e objetivava "entreter três a quatro vezes por mês, uma despretensiosa e feminil correspondência com as leitoras do 'Liberal do Pará'"’.

O fascínio para a leitura dessas cartas poderia ser alcançado, também, na forma como a escritora se apresentava, requerendo atenção e estima, diante da novidade do seu nome nas letras luso-brasileiras, e por pedir "por modo que através do Atlântico se enlacem os nossos pensamentos, e que se estabeleça entre a humilde folhetinista lisbonense e as

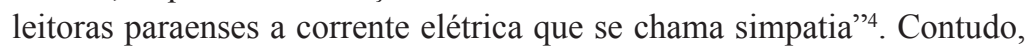
a escritora portuguesa não era de todo desconhecida, pois seu nome já se imprimia na imprensa paraense desde 28 de novembro de 1873 , conforme localizamos na seção "Comércio" desse mesmo jornal, quando seis anos antes de se tornar correspondente, já era anunciada nas páginas de $O \mathrm{Li}$ beral do Pará:

D. Guiomar Torrezão - a distinta e elegante escritora d. Guiomar Torrezão, acaba de ler no Ginásio um drama original em 3 atos, a que deu o título de Amor de Filha, esplêndida estreia daquele formosíssimo talento. É esperado com ansiedade na cena daquele teatro, onde vai entrar em ensaios.(O Liberal do Pará, $\mathrm{n}^{\circ}$. 270, 28/11/1873)

A referência ao nome da escritora portuguesa certamente facilitou a recepção das suas cartas na ocasião da publicação, acrescido ao fato que a autora ficciona uma interlocução particular entre ela e a leitora quando se lamentava por "Não ter o prazer de conhecer a leitora, e não poder, por conseguinte, mediante o auxílio dos meus modestos processos literários e

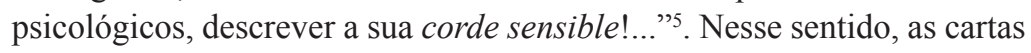
são dirigidas à criatura imaginada, possível leitor ou leitora, representação figurativa, projetada, a partir dos recursos desenvolvidos pelo que foi

${ }^{3}$ O Liberal do Pará. Belém. 1879. nº 169

${ }^{4}$ O Liberal do Pará. Belém. 1879. nº 169

${ }^{5}$ Ibidem. 
denominado "palestras familiares", e, com essa classificação já pressupunham uma intimidade afetuosa.

Além da cumplicidade pretendida, o teor dos escritos instigava a uma ruptura com o convencionalismo. Como, por exemplo, quando interpela a leitora acerca do seu conhecimento de mulheres ilustres, ressaltando os dotes que lhes tornava singular e, por isso, revolucionárias.

O diálogo íntimo perpassa as publicações quando o narrador propõe, na imagem da leitora, um sujeito que compartilha o diálogo. "Conversemos, leitora" é o início de algumas missivas, invocação que remete simpatia e amizade acentuada, principalmente, pela modéstia subliminar da correspondente "Como eu estou pressentindo a súbita vermelhidão reveladora que purpureará o rostinho de v. exc. ao chegar aquele período da carta da sua humilde correspondente".

São essas diversas formas de tratamento estabelecidas uma configuração estratégica de alcançar um público vário, com gostos e preferências diversas, porém já imaginado e caracterizado como os leitores pretendidos, seja para tratar de um assunto que remetesse à erudição, como quando citara Madame Geoffrin ${ }^{7}$, ou mademoiselle de Lespinasse ${ }^{8}$, além de mencionar também Madame du Deffand ${ }^{9}$, todas elas envolvidas na vida intelectual e cultural ao seu tempo e que, mais uma vez poderiam compor o perfil revolucionário feminino. Reunidas ao grupo das mulheres célebres, a escritora não deixou de mencionar Madame de La Fayette $^{10}$; a Marquesa de Sevigné ${ }^{11}$ e Madame de Maintenon ${ }^{12}$.

Escrever para um público feminino brasileiro oitocentista é saber que pode se deparar com dois oponentes fortes contra a educação feminina: a família e a Igreja. Num primeiro plano, a família, que, além de destinar maior atenção à educação dos filhos do sexo masculino, dificultava o acesso à leitura. Ao mesmo lado, a Igreja tinha como objetivo fazer da mulher uma mãe exemplar, sendo a maternidade a principal tarefa a desenvolver, além de manter as mulheres alheias e apartadas do mundo dos homens.

\footnotetext{
${ }^{6}$ O Liberal do Pará. Belém. 1879. no .175

${ }^{7}$ (Paris, 26/06/1699 - 06/10/1777)

${ }^{8}$ (Lion, 09/11/1732 - 23/05/1776)

${ }^{9}$ (Paris, 25/09/1697 - 23/10/1780)

${ }^{10}$ (Paris, 18/03/1634 - 25/05/1693)

${ }^{11}$ (Paris, 05/02/1626 - 17/04/1696)

${ }^{12}$ (Niort, 27/11/1635 - 15/04/1719)
} 
E é nesse tom amigável que Guiomar Torrezão procede com "as amáveis leitoras", a quem pede licença, na carta de 24 de agosto de 1879 , para de forma "despretensiosa", "permitir que eu lhes conte um pequenino romance"13.

A permissão para a leitura de um romance reporta-se às limitações que a leitura do gênero estava impelida. Só na cidade de Belém, eram inúmeros os periódicos religiosos destinados a proteger os leitores do romance, com ensaios avaliativos e previdentes do gênero.

Nessa publicação a autora experimentou trocar o gênero epistolar pela narrativa, a qual ela tratou como "um romance realista, como se diz hoje, ou por outra - uma história verdadeira, atual, destituída de lances dramáticos e de peripécias comoventes, vulgaríssimo incidente da nossa crônica lisbonense, mas que encerra no fundo uma eloquente lição" ${ }^{14}$. Ao identificar o romance como realista, Torrezão demonstrava estar atenta às novidades literárias da época.

A leitura de romances é explorada pela personagem Josephina, que se ocupava com algumas obras, "tirante o jornal de modas e o livro da missa, circunscreviam-se a seis ou oito romances, Rocambole, Os cavalleiros do punhal, Pepita Ximenes, O Primo Basilio"15, os quais despertaram paixões no coração da protagonista.

Os livros citados da preferência de Josephina correspondiam às novidades lidas não apenas na Europa, mas também no Brasil. As aventuras de Rocambole, de Ponson du Terrail, por exemplo, ganharam destaque em jornais franceses entre os anos de 1858 e 1859 e se espalharam pelo mundo. As obras contemporâneas às suas, como a do espanhol Juan Valera, Pepita Jimenez, lançada em 1874 e O Primo Basílio, do português Eça de Queirós, publicada em 1878, eram obras que poderiam remeter àquela leitora o espírito de aventura, paixões proibidas, traições, entre outras ações responsáveis por identificar esses livros como desaconselhados para as mulheres, pois provocariam a liberdade de pensamento, como o que ocorreu com a protagonista.

A identificação de que a protagonista estava diante de uma leitura proibida e de um romance capaz de comprometer a precedência de um comportamento "pecaminoso" da personagem foi enfatizada no trecho: "Josephina levara-o ocultamente para o quarto, e, defronte do transparente

\footnotetext{
${ }^{13}$ O Liberal do Pará. Belém. 1879. no. 192

${ }^{14}$ Ibidem

${ }^{15}$ Ibidem
} 
onde se osculava o par bucólico entre as ervas verde salsa, sarapintadas de papoulas sanguíneas, em presença do cisne encarnado, e à claridade misteriosa e láctea da lamparina, procedera à leitura do pecaminoso livro"16. Caracterizada como leitura licenciosa, o livro era lido, secretamente, à noite, sob a luz da lamparina, de forma ilícita. Não por coincidência, foi após a leitura de $O$ Primo Basílio, "nesta determinada crise psicológica, que Josephina flertou pela primeira vez"17, o que denotava a influência amorosa motivada pela leitura.

Esse "pequenino romance" realista integrou a coletânea de textos intitulada No Teatro e na Sala, publicada no ano de 1881, para a qual o então consagrado escritor português Camilo Castelo Branco escreveu o prefácio, argumentando sobre a escrita de Guiomar Torrezão: "Quantos escritores de primeira ordem escrevem em Portugal como v. ex. a'? Quem lhe pode dar exemplo de elegância de estilo, de profundeza e variedade de ideias indicativas de leitura vasta e metódica?".18

A deferência do romancista, notadamente reconhecido àquela altura, permite-nos balizar a obra de Guiomar Torrezão como notável entre os escritores coevos, mormente no que diz respeito à variedade de temas e no vasto conhecimento que ela demonstrava ter. Ainda no que diz respeito ao romance Faltara-lhes o berço, assim nomeado na coletânea com a frase conclusiva do romance-folhetim, advertimos que comparamos a primeira publicação - feita no jornal $O$ Liberal do Pará - com a da coletânea e notamos alterações significativas, marcadas pela experiência do espaço folhetim $^{19}$, mas que não consideramos pertinente apontar as modificações feitas pela folhetinista, haja vista que esse cuidado na revisão textual era comum entre os autores.

Os assuntos relacionados à moda estão presentes na carta de 07 de setembro de 1879, com o anúncio "Falemos de modas". Essa correspondência parecia deter-se exclusivamente à moda, mas, como sabemos, Torrezão usava o tema como pretexto para discorrer sobre assuntos de interesse ao mundo feminino, como a submissão da mulher a determinados modismos, por exemplo, o merinaque, artifício de moda que ela

${ }^{16}$ O Liberal do Pará. Belém. 1879. no .192

${ }^{17}$ Ibidem

${ }^{18}$ Camilo Castelo Branco. In: No Teatro e na Sala. Lisboa: sem editora, 1881.

${ }^{19}$ In: MEYER, Marlyse. FOLHETIM: uma história. São Paulo: Companhia das Letras. 1996. 
repudiava e dizia ser contra "enfiar o corpo numa dessas monstruosas gaiolas de ferro e de baleia, tecidas com fios de pita e de crina" ${ }^{20}$. A autora convocava suas leitoras a não aceitarem tal forma de agressão e dizia estar "Confiando, pois, no juízo prudencial e no fino bom gosto das leitoras, e contando com a sua adesão, desenrolo o estandarte bélico e coloco-me desde já em pé de guerra contra o inimigo, isto é, contra o merinaque!"21.

Guiomar Torrezão opunha-se àquilo que era impingido pela moda parisiense, a dizer: "Declaro às leitoras que passo para a oposição e que com todos os adjetivos da minha gramática de Repórter e com todas as indignações do meu bom senso protesto contra essa absurda e ridícula inovação" "22. Embora apresentasse as novidades da moda europeia, especialmente a francesa, dava seu parecer contrário ao que ela considerava ser "o instrumento passivo dos caprichos absurdos das modistas parisienses, inspirados às vezes, segundo parece, pela intenção maligna de as desprestigiar" 23 . A autora cumpria o seu papel de "repórter", mas não se isentava de tentar influenciar as leitoras paraenses, pois quem estava por trás dessa missiva, aparentemente ingênua, era uma das mais importantes mediadoras culturais a escrever para um jornal da província do Pará.

$\mathrm{Na}$ carta publicada em 12 de outubro de 1879, a folhetinista pedia "Que a leitora perdoe se deixando-me ir presa da fascinadora, que Pascal chamou a folle $d u$ logis, tantas vezes me desvio do principal assunto destas cartas" ${ }^{24}$. Consciente de que suas cartas eram construídas com uma intenção além da moda e da imaginação, procurava agir de maneira que suas leitoras - e também os maridos - não se apercebessem desse propósito e, portanto, era sutil nos conselhos e sempre se dirigia às mulheres, justificando:

Estas cartas criaram-se expressamente para a leitora, para que v. exc. por meio delas obtenha as mais circunstanciadas noções da toilette, os mais preciosos elementos, os mais finos e complexos segredos da estética aplicada, mediante a qual o vestuário deixando de ser uma coisa puramente secundária passa a ser um fato importantíssimo. (O Liberal do Pará, nº. 233, 12/10/1879)

\footnotetext{
${ }^{20}$ O Liberal do Pará. Belém. 1879. nº 207

${ }^{21}$ Ibidem

${ }^{22}$ Ibidem

${ }^{23}$ Ibidem

${ }^{24}$ O Liberal do Pará. Belém. 1879. nº 233
} 
Assim sendo, mesmo as leitoras mais atentas, tanto aos informes de leitura e comportamento, quanto aos de toalete, assimilavam o teor das cartas supondo que a escritora, ao variar as informações, apenas devaneava, porque era dessa maneira que ela se justificava: "Que a leitora, porém, me consinta de vez em quando umas ligeiras divagações" 25 .

Em 04 de janeiro de 1880, três meses após a última missiva, certas leitoras encontravam as desculpas e apupo da escritora: "Que longa ausência, leitora [...] Como a sua pobre folhetinista se daria por bem paga das saudades que a pungiram com os seus agudos espinhos se pudesse obter a certeza que a leitora as partilhara!...”26, o que denotava a cordialidade, bem como a necessidade de manter estreita relação com a leitora paraense, justificando "Porque a sua obscura informadora, minha senhora, não tem outra ambição que não seja a de vibrar a corde sensible de v. exc."27.

A conversa com as leitoras referenciava a atuação e importância da mulher na história da humanidade,quando argumentava que "Nós as mulheres, segundo afirmaram os srs. romancistas psicológicos, somos as legendárias esfinges cujo eterno segredo ninguém ainda conseguiu decifrar" ${ }^{\prime 2}$. E como forma de ilustração referenciava mulheres imortalizadas por sua atuação ao longo dos tempos, entre as quais Eva, Dalila e Cleópatra. Notemos que as personagens citadas pela folhetinista representam mulheres fortes, sedutoras e capazes de persuadir o homem à satisfação de sua vontade, como foi o caso dessas.

Antes de adentrar no assunto de moda, Torrezão interpelava as leitoras, solicitando, "Se as minhas benévolas leitoras brasileiras partilharem a convicção da sua humilde repórter, não poderão obter mais deliciosa e grata recompensa senão estas 'cartas lisbonenses' que lhes são exclusivamente consagradas" ${ }^{29}$, ou seja, ela apelava por cumplicidade de ideia e tentava convencer suas leitoras a comungarem do mesmo pensamento, $\mathrm{o}$ que ratifica a perspectiva que compreendemos a respeito da tentativa de Guiomar influenciar culturalmente as leitoras paraenses, a quem as cartas eram "exclusivamente consagradas".

No mesmo mês de janeiro a escritora compartilha com o público notícias sobre as eleições para deputado em Portugal: "vejo neste momen-

${ }^{25}$ Ibidem

${ }^{26}$ O Liberal do Pará. Belém. 1880. nº. 03

${ }^{27}$ Ibidem

${ }^{28}$ Ibidem

${ }^{29}$ Ibidem 
to, em cima da minha pequena mesa de trabalho, um número do 'Paris Murcia', cuja ambicionada posse os parisienses disputam a esta hora a murro... britânico!" ${ }^{30}$. As anotações acerca da atualidade permitiam a inferência sobre o conhecimento privilegiado da escritora, "uma das mais laboriosas cultôras da prosa ligeira, e das mais bem dotadas organizações litterarias do paiz"31. Depois da leitura do Paris Murcia, pondera: "Acomete-me um desejo doido de roubar-lhe algumas joias e de presentear com elas as minhas formosas leitoras paraenses" ${ }^{\prime 2}$. As joias de que ela se referia seriam os escritos daqueles que se consagraram nas artes em geral como, "Coppé", de quem ela dizia que os versos tinham as "cintilações nítidas do diamante", "Dumas Filho, o vigoroso polemista", "Madame de Girardin, a musa do folhetim", entre outros.

Sobre a organização dessa coletânea de cartas, importa ressaltar que Guiomar Torrezão se inspirava em Mme. de Giradin, autora das Cartas Parisienses, escritas com os mesmos propósitos, e com essas referências incutia, conscientemente, na mente das leitoras um cabedal cultural inimaginável de ser enviado por uma correspondente portuguesa ao Pará. Mas ela era ciente de que esse público feminino estava ávido pelas novidades europeias, tanto que dizia "Resisto, porém, à tentação lembrando-me que é provável que o 'Paris Murcia' chegue às mãos da leitora muito antes da minha carta" ${ }^{33}$. Supunha, portanto, a romancista que o grupo das leitoras paraenses acompanhava as notícias de lançamentos e jornais, inclusive dos europeus que não tardavam a aportar na província, o que indica, mais uma vez, que as cartas eram destinadas a uma parte exclusiva de leitoras, cultas.

Na sequência da carta, Torrezão discorria sobre o comportamento de algumas mulheres que, segundo ela, viviam de aparência e pouco se preocupavam com os estudos, pois a maioria vislumbrava um casamento por conveniência e se mantinha indiferente ao julgamento da sociedade. Sobre esses modos, ela dizia que "as meninas riam, o riso desafinado e agudo dos cérebros ocos, falavam, gesticulavam, marchavam ao som da música, como um tambor mor, tinham frases repinicadas, de um con-

\footnotetext{
${ }^{30}$ O Liberal do Pará. Belém. 1880. nº 14

${ }^{31}$ Ibidem

${ }^{32}$ Ibidem

${ }^{33}$ Ibidem
} 
vencionalismo banal, que davam vontade de chorar!"34, ou seja, ela se demonstrava penalizada em contemplar a postura das moças indiscretas, as quais "Os homens fitavam-nas petulantemente na promiscuidade animal de um nivelamento desrespeitoso, com malícias felinas e desprezo tácito" 35 .

Esse tipo de comportamento feminino era repreendido por Guiomar, que, ao mesmo tempo, se compadecia da atitude das meninas, que provocavam "um dó profundo e intenso dessas desgraçadas raparigas, grotescas nos seus vestuários pelintras e nas suas pretensões idiotas, como o produto caricato de uma educação falseada e de uma impostura reles que obedeciam fatalmente as condições viciadas de seu meio" ${ }^{36}$. Nessa carta, percebemos uma denúncia à condição degradante da mulher, principalmente da rapariga que se submetia às mais humilhantes situações para tentar encontrar um casamento ou, às vezes, de forma ilícita, um amante que lhe sustentasse os luxos, isso porque "fora levada pela ridícula ambição de parecer rica"37. Havia uma exposição da realidade de muitas mulheres que tentavam ostentar aquilo que não possuíam, e era essa situação que a autora apontava por meio do folhetim.

A coletânea de cartas soma doze publicações, todas compostas com o mesmo fim, o diálogo com a identidade feminina ${ }^{38}$ em suas realizações que ultrapassavam o gosto pela moda ou pelas novidades, mas a contemplava como ser humano em suas realizações maiores e necessárias. E as outras cinco cartas? Estas serão motivo de outro artigo, quando teremos oportunidade de detalhar mais uma vez a relação íntima e cúmplice entre Guiomar Torrezão e as leitoras paraenses.

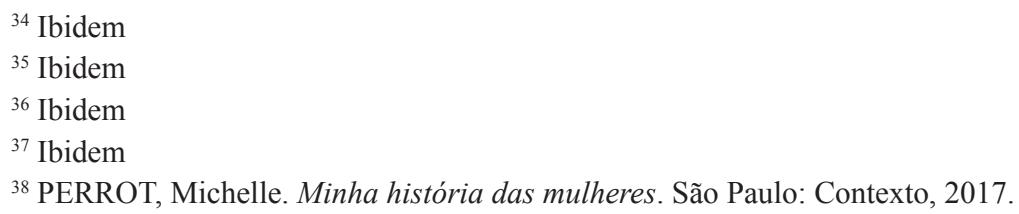




\section{REFERÊNCIAS}

ALMEIDA, Fialho de. Figuras de Destaque. Lisboa: Livraria Clássica Editora, 1923.

BARROS, Thereza Leitão de. Escritoras Portuguesas. Vol. II. Lisboa: 1824.

MEYER, Marlyse. Folhetim: Uma história. São Paulo: Companhia das Letras. 1996

PERROT, Michelle. Minha história das mulheres. São Paulo: Contexto, 2017. TORREZÃO, Guiomar. No teatro e na sala. Lisboa: sem editora, 1881.

\section{Jornais}

O Liberal do Pará. Belém. 1873. N. 270.

O Liberal do Pará. Belém. 1879. nº 169, nº 175, nº 192, nº 207, nº 233.

O Liberal do Pará. Belém. 1880, nº 3, nº 14.

Recebido em: 29/09/2018

Aceito em: 28/01/2019 